\title{
Exenatide modulates tumor- endothelial cell interactions in human ovarian cancer cells
}

\section{Agnieszka Kosowska', Enrique Gallego-Colon', Wojciech Garczorz', Agnieszka Kłych-Ratuszny1, Mohammad Reza F Aghdam', Michał Woźniak', Andrzej Witek ${ }^{2}$, Agnieszka Wróblewska-Czech ${ }^{2}$, Anna Cygal ${ }^{2}$, Jerzy Wojnar ${ }^{3}$ and Tomasz Francuz ${ }^{1}$}

'Department of Biochemistry, School of Medicine in Katowice, Medical University of Silesia, Katowice, Poland ${ }^{2}$ Department of Gynaecology and Obstetrics, School of Medicine in Katowice, Medical University of Silesia, Katowice, Poland

${ }^{3}$ Department of Internal Medicine and Oncological Chemotherapy, School of Medicine in Katowice, Medical University of Silesia, Katowice, Poland
Correspondence

should be addressed

to A Kosowska

Email

akosowska@sum.edu.pl

\begin{abstract}
Diabetes and cancer are prevalent diseases whose incidence is increasing globally. Diabetic women have a moderate risk increase in ovarian cancer, suggested to be due to an interaction between these two disorders. Furthermore, patients manifesting both diseases have associated worse prognosis, reduced survival and shorter relapsefree survival. According to current recommendations, incretin drugs such as Exenatide, a synthetic analog of Exendin-4, and Liraglutide are used as therapy for the type 2 diabetes (T2D). We studied the effects of GLP-1 and Exendin-4 on migration, apoptosis and metalloproteinase production in two human ovarian cancer cells (SKOV-3 and CAOV-3). Exendin-4 inhibited migration and promoted apoptosis through caspase 3/7 activation. Exendin-4 also modulated the expression of key metalloproteinases (MMP-2 and MMP-9) and their inhibitors (TIMP-1 and TIMP-2). Vascular endothelial cells, which contribute to the formation and progression of metastasis, were also analyzed.

TNF- $\alpha$-stimulated endothelial cells from iliac artery after Exendin- 4 treatment showed reduced production of adhesion molecules (ICAM-1 and VCAM-1). Additionally, incretin treatment inhibited activation of apoptosis in TNF- $\alpha$-stimulated endothelial cells. In the same experiment, MMPs (MMP-1 and MMP-9), which are relevant for tumor development, were also reduced. Our study demonstrated that incretin drugs may reduce cancer cell proliferation and dissemination potential, hence limiting the risk of metastasis in epithelial ovarian cancer.
\end{abstract}

\author{
Key Words \\ - Exenatide \\ - ovarian cancer \\ - endothelial cells \\ - apoptosis \\ - MMPs
}

\section{Background}

Cancer and diabetes are growing health problems worldwide. Epidemiological data show an increase in the prevalence of those diseases. Their coexistence is more common than estimated on the basis of their frequency in the population suggesting a cause-effect interaction between cancer and type 2 diabetes (T2D) (1, 2). Furthermore, the coexistence of both diseases is associated with worse prognosis and higher mortality (3). In the clinical setting, several groups of drugs are used in the treatment of diabetes including insulin, sulfonylurea and metformin. Insulin and sulfonylurea treatment in patients under anti-cancer therapy have been associated with worse prognosis, lower overall survival rate and shorter time-to-relapse as compared to patients on metformin or

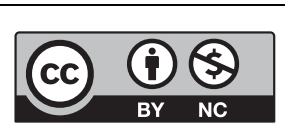

This work is licensed under a Creative Commons Attribution-NonCommercial 4.0 International License. 
patients without diabetes. To date, metformin has proven to give beneficial effects in patients with cancer, leading to longer survival rates, better prognosis and in vitro inducing apoptosis of some tumor cell lines (4).

Alternatively, incretin mimetic drugs are a relatively new group of drugs used in the treatment of diabetes that are currently recommended by American Diabetes Association in dual therapy with metformin for the treatment of $\mathrm{T} 2 \mathrm{D}(5,6)$. The mechanism of action of incretin mimetic drugs is through the binding to glucagon-like peptide-1 receptor (GLP-1R) in pancreatic beta cells stimulating insulin secretion. The two most important natural incretin hormones are glucagon-like peptide-1 (GLP-1) and glucose-dependent insulinotropic polypeptide (GIP). However, GIP and GLP-1 are not used as drugs, due to their rapid hydrolysis by dipeptidyl peptidase-IV (DPP-IV). Consequently, pharmacological approaches are focused on the use of GLP-1 analogs, such as Liraglutide and Exenatide (a synthetic version of Exendin-4), with extended half-life and resistance to DDP-IV enzymatic degradation. Interestingly, GLP-1R is present on various types of cells, among which include cancer cells $(7,8)$.

The high mortality rate in ovarian cancer patients is mostly due to a late diagnosis, at which time the cancer has metastasized throughout the peritoneal cavity and omentum (9). Epithelial ovarian cancer can disseminate via transcoelmic, hematogenous or lymphatic route (10). Cancer metastasis is facilitated by the remodeling of the extracellular matrix (ECM) at the tumor site (11) and during invasion of tissues (12). Breakdown of the ECM components is carried out by matrix metalloproteinases (MMPs), a family of proteolytic enzymes. MMP activity is tightly controlled mainly by tissue inhibitors of metalloproteinase (TIMPs). Ovarian cancer cells alter MMP/TIMP ratio creating a microenvironment promoting cancer cell migration and metastasis $(11,13)$. Interestingly, pro-inflammatory environment modulates ovarian cancer cells (9) and endothelial cells $(14,15)$ to stimulate the synthesis or activation of various MMPs to aid in tumor growth, invasion and eventual metastasis. Furthermore, increase in MMP-2 and MMP-9 production has been associated with increased angiogenic response by VEGF expression potentially affecting metastatic potential of cancer cells (16).

The role of GLP-1 analogs on cancer cell growth and invasion both in vitro and in vivo is yet to be elucidated. Incretins have shown to inhibit growth and enhance apoptosis of cancer cells through inhibition of the PI3K/Akt pathway for some cell lines of breast (17), colon cancer (18) and ovarian cancer (19). Thus, understating of the role of GLP-1 analogs has important clinical implication in the design of novel anti-cancer therapies emphasizing the potential benefits of combining both incretins with chemotherapy-cytostatic drugs. In the present study, we investigated whether incretin agonist, Exendin-4, influenced ovarian cancer and vascular endothelium and this had a carry-on effect on tissue remodeling.

\section{Materials and methods}

\section{Cell lines}

Human ovarian cancer cell lines, SKOV-3 and CAOV-3 (ATCC), were cultured in DMEM (Sigma) or McCoy (Sigma) medium, respectively, with $1 \%$ antibiotics (Sigma) and $10 \% \mathrm{FBS}$ (Sigma) at $37^{\circ} \mathrm{C}$ in $5 \% \mathrm{CO}_{2}$ humidified incubator. Human Iliac artery endothelial cells and human aortic endothelial cells (Lonza, Basel, Switzerland) were cultured in EBM-2 culture medium as previously described (20). Three ovarian tumor cell lines were isolated de novo from anonymous patients undergoing surgical removal of the ovaries due to ovarian cancer with patients' consent. Biopsies were obtained after approval of the ethic committee of the Medical University of Silesia (KNW/0022/KB1/122/14). Prior to incubation, the ovarian cancer biopsies were washed in HEPES buffer to remove blood. Then, the sections were cut into pieces with a diameter of approx. $1 \mathrm{~mm}$ and placed in a culture Petri dish. Tumor cells were isolated using the 'explant method' $(21,22)$ and cultured under the same conditions as SKOV-3 cells.

\section{Transwell migration assays}

Ovarian cancer cell migration was conducted using an 8- $\mu \mathrm{m}$ transwell system (Greiner Bio-One, Kremsmünster, Austria) in a 24-well plate format. For migration assay, $2 \times 10^{5}$ cells were placed in the upper chamber of the transwell in $200 \mu \mathrm{L}$ medium (0.5\% FBS), Exendin-4 (50 nM, Sigma), GLP-1 (100 nM, Sigma), GLP-1 antagonist 9-36 $(50 \mathrm{nM})$ (Tocris, Bristol, UK). Cells were pre-incubated with Exendin- 4 for $24 \mathrm{~h}$ when appropriate. Cells were induced to actively migrate through membrane into the lower compartment containing $600 \mu \mathrm{L}$ of DMEM and monocyte chemoattractant protein (MCP-1) at 10 nM (23). Cells were cultured for $24 \mathrm{~h}$. Migrated cells in the underside of the membrane were detached with trypsin and fluorescently labeled with Calcein-AM $(8 \mu \mathrm{M})$ for $45 \mathrm{~min}$.

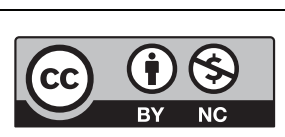

This work is licensed under a Creative Commons Attribution-NonCommercial 4.0 International License. 
A number of migrating cells were assessed by measuring fluorescence (excitation wavelength of $485 \mathrm{~nm}$ and an emission wavelength of $520 \mathrm{~nm}$ ) with a microplate reader on Infinite M200 (TECAN, Männedorf, Switzerland).

\section{Viability, cytotoxicity and apoptosis assays}

Ovarian cancer cells were seeded into a 96-well plate at a total density of $2 \times 10^{4}$ cells per well in appropriate cell culture medium. Cells were pre-incubated with Exendin- 4 for $24 \mathrm{~h}$ when appropriate and then incubated with Camptothecin (100 nM) or Exendin-4 (50 nM) for $24 \mathrm{~h}$. Viability, cytotoxicity and caspase activation were determined using ApoTox-Glo Triplex assay (Promega) according to the manufacturer's protocol.

\section{Immunoblotting}

Cells were lysed in PathScan lysis buffer (Cell Signaling Technology) containing phenylmethylsulfonyl fluoride (Sigma) and protease inhibitor (Roche). The protein samples were separated by SDS-PAGE. Proteins were transferred into low autofluorescence Immobilon-FL PVDF membrane (Millipore) and incubated with either antibody, GLP-1R (ab39072, Abcam) at 1:1000 or GAPDH (Sigma) at 1:5000. Goat anti-rabbit secondary antibody conjugated with fluorescent dye IRDye800 (LI-COR Biosciences, Lincoln, NE, USA) was used. The proteins of interest were visualized by using LICOR Odyssey Infrared Imaging System.

\section{Fluorescent bead-based Luminex cytokine assay}

Analysis of MMPs and TIMPs protein concentration was performed in cell medium using multiplex, bead-based (Luminex) assays on a Bio-Plex200 suspension array system according to each manufacturer's instructions. Data were acquired on a validated and calibrated Bio-Plex 200 system (Bio-Rad Laboratories) and analyzed with Bio-Plex Manager 6.0 software (Bio-Rad Laboratories) with a detection target of 50 beads per region, low RP1 target for CAL2 calibration and recommended doublet discriminator gates of 5000-25,000 for Bio-Plex. The median fluorescence intensity was measured. Bio-Plex Pro Human MMP 9-Plex Panel (Bio-Rad Laboratories) was used for detection of MMPs. Bio-Plex Pro Human Cytokine 27-plex assay (Bio-Rad Laboratories) was used for detection of TNF- $\alpha$ and VEGF. Analysis of phosphoIкB (Ser32) and IкB was performed in cell medium using multiplex, bead-based (Luminex xMAP, Merck) as described earlier and according to manufacturer's instructions.

\section{Determination of adhesion molecule levels}

ICAM-1 and VCAM-1 protein concentrations in IAEC cells were quantified by Enzyme Linked ImmunoSorbent Assay (ELISA) by using DuoSet ELISA kits (R\&D Systems), according to the manufacturer's instructions. ET-1 was assayed using RnD's QuantiGlo assay (R\&D Systems).

\section{Statistical analysis}

Data are presented as mean values \pm s.E.M. Data were analyzed with GraphPad-Prism 5.0 (Graphpad Software), and differences were considered statistically significant at $P<0.05$.

\section{Results}

\section{Exendin-4 reduces migration of ovarian cancer cells through the GLP-1R}

The main effects of GLP-1 analogs are achieved through binding to the GLP-1R. In SKOV-3 and CAOV-3 cell lines, GLP-1R receptor presence was shown in Western blot analysis. GLP-1R was also observed in ovaries of patients with adenocarcinoma (Fig. 1A).

In transwell-based migration assay, Exendin-4 attenuated the MCP-1 induced migration in both SKOV-3 and CAOV-3 cell lines (Fig. 1B and C). Exendin-4 $(50 \mathrm{nM})$ was added into the upper well and invasiveness was reduced by $13 \%$ in SKOV-3 cells and by $11 \%$ in CAOV-3 cells. Pre-treatment of Exendin- 4 for $24 \mathrm{~h}$ further attenuated the migration potential by $22 \%$ in SKOV-3 cells and by $29 \%$ in CAOV-3 cells. In addition, GLP-1R antagonist $(50 \mathrm{nM})$ reversed the inhibitory effects induced by Exendin- 4 in both cell lines.

\section{Incretin effects on apoptotic and viability}

To assess the influence of incretin drugs on apoptosis and cell viability, SKOV-3 and CAOV-3 cells were stimulated with $50 \mathrm{nM}$ of Exendin- 4 for $24 \mathrm{~h}$ with or without the pre-treatment with Exendin- 4 for $24 \mathrm{~h}$. In both analyzed cancer cell lines, Exendin- 4 induced the activation of caspase $3 / 7$ by $31 \%$ in SKOV-3 cells and by $38 \%$ in CAOV-3 cells. Pre-treatment with Exendin- 4 further increased activation of caspases by $56 \%$ in

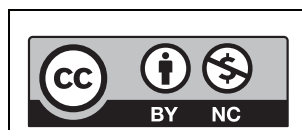

This work is licensed under a Creative Commons Attribution-NonCommercial 4.0 International License. 
A

GLP-1R

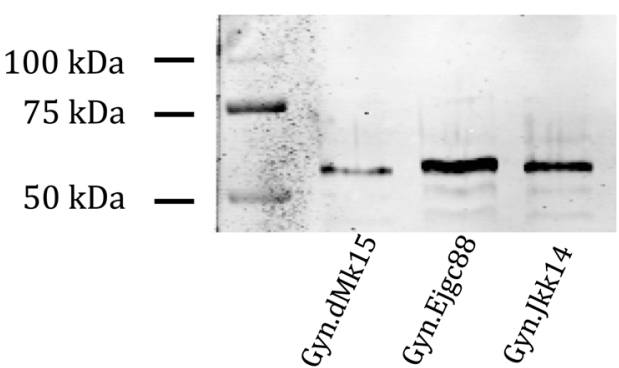

SKOV-3

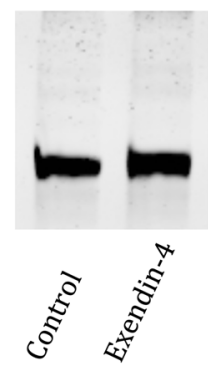

CAOV-3

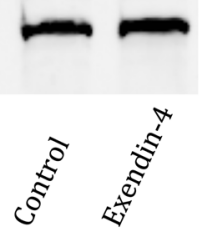

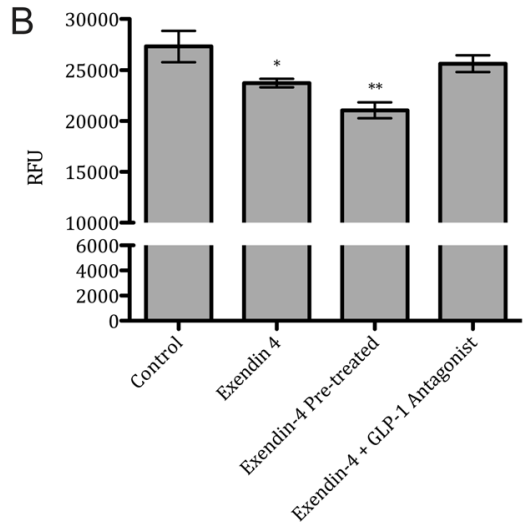

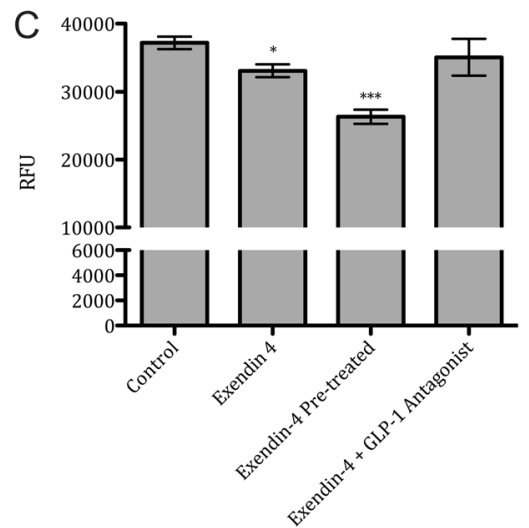

Figure 1

GLP-1R Western blot and transwell-based migration assay. Representative Western blot image of protein extracts from SKOV-3, CAOV-3 and patient biopsies (A). Ovarian cancer cell lines were stimulated for $24 \mathrm{~h}$ with Exendin-4 (50 nM), Exendin-4 ( $50 \mathrm{nM})$ pre-treatment for $24 \mathrm{~h}$ and GLP-1 Antagonist 9-36 (50 nM) in both SKOV-3 (B) and CAOV-3 (C). Relative fluorescence units (RFU). Mean values \pm S.E.M. are shown. $n=3$ per group. $\star P<0.05, * * P<0.01, * * * P<0.001$ Control vs different conditions. One-way ANOVA followed with Dunnett's post hoc.
SKOV-3 cells and by 50\% in CAOV-3 cells (Fig. 2A and D). Both cell lines displayed a similar pattern of viability.

In both cancer cell lines, stimulation with Exendin-4 with or without $24 \mathrm{~h}$ pre-treatment caused no significant changes in viability. Camptothecin (CPT) treatment caused a reduction in viability in SKOV-3 cells by $27 \%$ and by $28 \%$ in CAOV-3. Interestingly, Exendin- 4 and CPT together further reduced viability of SKOV-3 cells by $44 \%$ and by $52 \%$ in CAOV-3. Additionally, cells pre-treated with Exendin- 4 and incubated with Exendin- 4 and CPT together caused a reduction in viability of SKOV-3 cells by $27 \%$ and by $38 \%$ in CAOV-3 (Fig. 2B and E).

In parallel, activation of GLP-1R signaling pathway was determined by multiplex analysis. Exendin-4 treatment decreased the phospho-IкB protein levels by $43 \%$ in SKOV-3 and by $36 \%$ in CAOV-3. Similarly, GLP-1 (100 nM) decreased the phospho-IкB protein levels by $40 \%$ in SKOV-3 and by $46 \%$ in CAOV-3 (Fig. 2C and F). The group treated with Camptothecin, a potent chemotherapeutic drug, also displayed a reduced

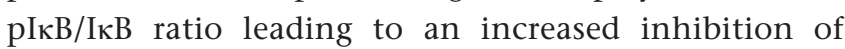
$\mathrm{NF}-\kappa \mathrm{B}(24)$.

\section{Distinct metalloproteinase production in Exendin-4- stimulated ovarian cancer cells}

Ovarian cancer cells, SKOV-3 and CAOV-3, were incubated with TNF- $\alpha$ and incretin mimetic drugs and MMP levels were evaluated. MMP-1, MMP-2, MMP-7, MMP-9, MMP-10 and MMP-13 protein concentrations of cell culture mediums were assessed in both cancer cell lines upon stimulation with TNF- $\alpha$, Exendin- 4 and GLP-1 separately or in combination. Only detectable levels of MMPs were observed in the SKOV-3 cell line, whereas MMP levels were under detection limits for CAOV-3. After TNF- $\alpha$ incubation, treatment with either Exendin-4 or GLP-1 moderately decreased the protein level of all MMPs when compared with the TNF- $\alpha$ (Fig. 3). Upon TNF- $\alpha$ incubation, either Exendin-4 or GLP-1 caused an MMP-1 reduction by $14 \%$ and 19\%, respectively (Fig. 3A). MMP-2 reduction was $23 \%$ and $47 \%$, respectively (Fig. 3B). MMP-7 reduction was $22 \%$ and $32 \%$, respectively (Fig. 3C). MMP-9 reduction was $15 \%$ and $21 \%$, respectively (Fig. 3D). MMP-10 reduction was $16 \%$ and $37 \%$, respectively (Fig. 3E). MMP-13 reduction by $27 \%$ was observed only when Exendin-4 was given (Fig. 3F). Interestingly, both http://www.endocrineconnections.org DOI: 10.1530/EC-17-0294 (c) 2017 The authors Published by Bioscientifica Ltd
This work is licensed under a Creative Commons Attribution-NonCommercial 4.0 International License. 


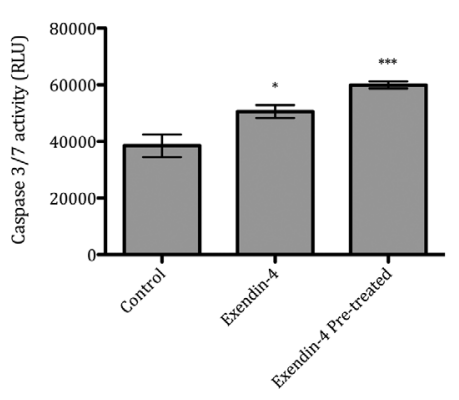

D

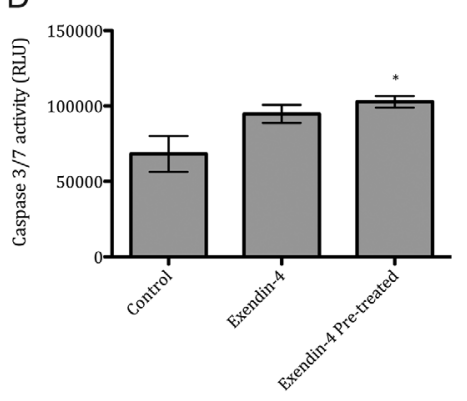

B

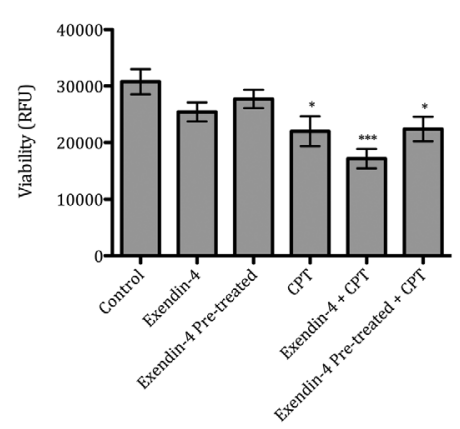

E

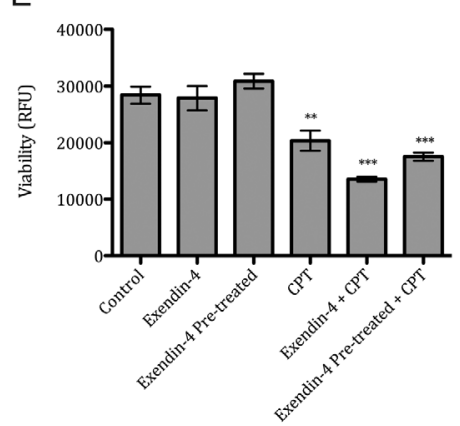

C

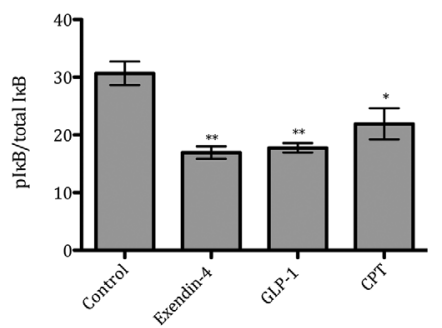

$\mathrm{F}$

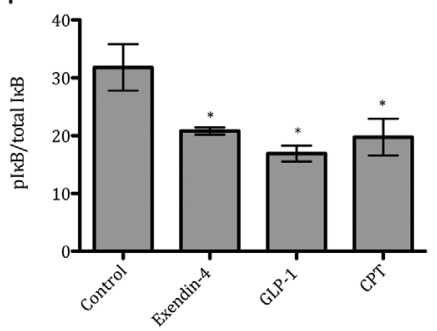

Figure 2 Exendin-4 effects on apoptosis, cell viability and signaling pathway. Ovarian cancer cell lines were stimulated for $24 \mathrm{~h}$ with Exendin-4 (50 $\mathrm{nM}$ ), Exendin-4 (50 nM) pre-treatment for $24 \mathrm{~h}$ and Camptothecin (CPT, $100 \mathrm{nM}$ ) in both SKOV-3 (A, B, C) and CAOV-3 (D, E, F). Caspase 3/7 activation in SKOV-3 (A) and CAOV-3 (D), cell viability in SKOV-3 (B) and CAOV-3 (E) and phospholkB in SKOV-3 (C) and CAOV-3 (F) was analyzed. Relative fluorescence units (RFU). Mean values \pm S.E.M. are shown. $n=3$ per group. ${ }^{*} P<0.05, * * P<0.01, * * * P<0.001$ Control vs different conditions. One-way ANOVA followed with Dunnett's post hoc.

Exendin-4 and GLP-1 caused a reduction in MMP-2 and MMP-9 protein levels in non-TNF- $\alpha$ groups when compared with the unstimulated group (Fig. 4B and D); this reduction is not observed for the other MMPs.

\section{Exendin-4 modulates angiogenic factors and inhibits TNF- $\alpha$ endothelial cell apoptosis}

We assessed the protein levels of VEGF in both cancer cell lines after stimulation with CPT and incretin agonists. VEGF protein levels were reduced in both cell lines when compared to the control group (Fig. 4). Exendin-4 caused a reduction by $14 \%$ and GLP- 1 by $25 \%$ in SKOV-3 cells (Fig. 4A) and a reduction by $22 \%$ and GLP-1 by $19 \%$ in CAOV-3 cells (Fig. 4D). We also assessed the TNF- $\alpha$ in both cancer cell media after stimulation with CPT and incretin drugs. TNF- $\alpha$ protein levels were reduced in both cell lines when compared to the control group. Exendin- 4 caused a reduction by $43 \%$ and GLP-1 by $50 \%$ in SKOV-3 cells (Fig. 4B), whereas in CAOV-3 cells Exendin-4 caused a reduction by $22 \%$ and GLP-1 by $21 \%$ (Fig. $4 \mathrm{E}$ ). No changes were observed in inflammatory cytokines such as IL-6 and
IL-8 (Supplementary data 1, see section on supplementary data given at the end of this article).

Interestingly, endothelial cells from aorta, coronary artery and iliac artery showed differences in the expression levels of the GLP-1R (Fig. 4C). GLP-1R agonist treatment reduced the TNF- $\alpha$-mediated apoptosis in iliac artery endothelium. Exendin- 4 treatment at $1 \mathrm{nM}$ or $10 \mathrm{nM}$ reduced caspase $3 / 7$ activation by $27 \%$ and $31 \%$, respectively. GLP-1 treatment at $10 \mathrm{nM}$ or $100 \mathrm{nM}$ reduced caspase $3 / 7$ by $32 \%$ and $30 \%$, respectively (Fig. 4 F).

\section{Modulation of adhesion molecules, metalloproteinases and inhibitors of metalloproteinase production in endothelial cells after GLP-1 agonist treatment}

The protein levels of selected adhesion molecules were quantified in TNF- $\alpha$-stimulated endothelial cells (Fig. 5). Upon treatment with GLP-1R agonists (10nM and $100 \mathrm{nM})$, only the higher concentration of either analog significantly reduced the levels of intracellular adhesion molecule 1 (ICAM-1) by $22 \%$ and $20 \%$, respectively 
A

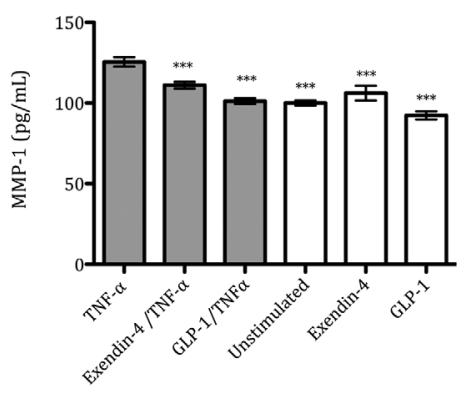

D

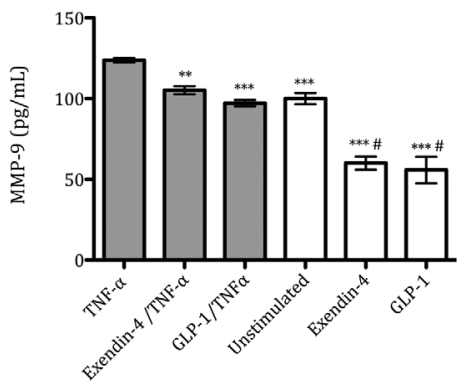

B

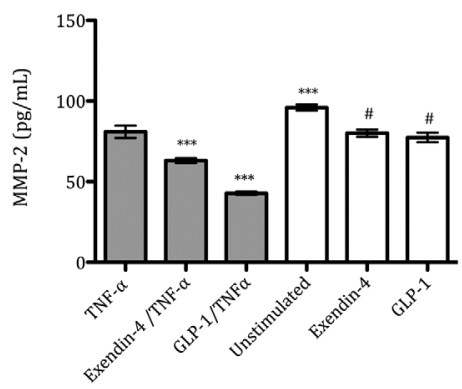

E

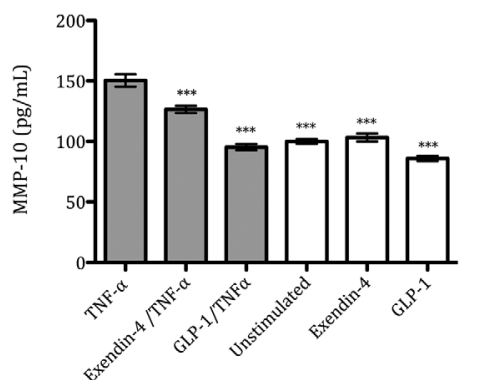

C

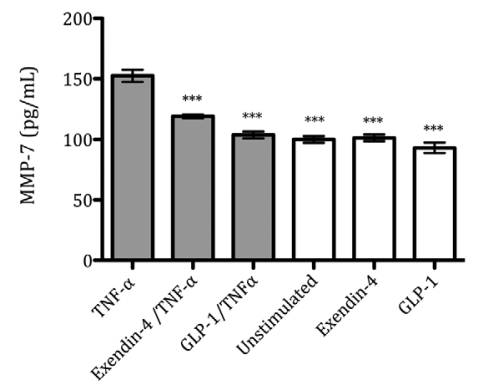

$\mathrm{F}$

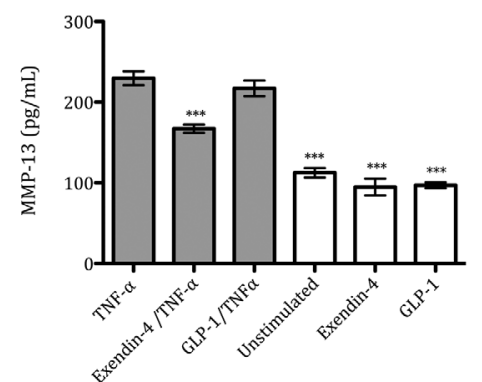

Figure 3 TNF- $\alpha$-mediated metalloproteinase profile after Exendin-4 treatment in SKOV-3 cancer cells. Protein levels of MMP-1 (A), MMP-2 (B), MMP-7 (C), MMP-9 (D), MMP-10 (E) and MMP-13 (F) were analyzed by multiplex analysis after $24 \mathrm{~h}$ incubation with TNF- $\alpha(10 \mathrm{ng} / \mathrm{mL})$, Exendin-4 (50 $\mathrm{nM})$ and GLP-1 agonist (100 nM). Mean values \pm s.E.M. are shown. $n=3-6$ per group. Gray bars, TNF- $\alpha$-stimulated. White bars, non-TNF- $\alpha$-stimulated. ${ }^{*} P<0.05$, $* * P<0.01, * * * P<0.001$ TNF- $\alpha$ vs different conditions. ${ }^{*} P<0.05$ Unstimulated vs Exendin-4 or GLP-1 group. One-way ANOVA followed with Dunnett's post hoc.

(Fig. 2A). Vascular adhesion molecule was also reduced by $50 \%$ and $43 \%$, respectively (Fig. 2B). The levels of other adhesion molecules, P-selectin and Endothelin-1 (ET-1), remained unchanged (Supplementary data 2).

Endothelial cells in the presence of TNF- $\alpha$ treated with Exendin- 4 at $10 \mathrm{nM}$ only significantly reduced the levels of MMP-1 by $43 \%$ (Fig. 5C) and MMP-9 by $89 \%$ (Fig. 5D). Conversely, the levels of TIMP-1 and TIMP-2 (Fig. 5E and F), but not TIMP-3 (Supplementary data 2), were markedly increased in the higher concentration of both incretins. In the presence of TNF- $\alpha$, Exendin- 4 and GLP- 1 caused an increase in TIMP-1 by $51 \%$ and 50\%, respectively (Fig. 5E) and an increase in TIMP- 2 by $65 \%$ and $52 \%$, respectively (Fig. 5F).

\section{Discussion}

Evidence and epidemiological observational studies show an increase in the prevalence of both diabetes and cancer; thus, clinicians will have to face treatment of both conditions in the patient at the same time. In clinical environment, GLP-1 analogs and DDP-4 inhibitors are currently being used to treat T2D. Early data obtained from health register analysis and observational studies

$\begin{array}{lr}\text { http://www.endocrineconnections.org } & \text { ○ } 2017 \text { The authors } \\ \text { DOI: } 10.1530 / \text { EC-17-0294 } & \text { Published by Bioscientifica Ltd }\end{array}$

have suggested that incretin drugs increase incidence of cancer, especially pancreatic cancer, in patients on incretin therapies (25). However, randomized clinical trials showed that incretin-based drugs were not associated with an increased risk of pancreatic cancer (26). Overall, the scarce in vitro data limit our understanding of the role of incretins and cancer. Although the mechanisms of action of GLP-1 analogs are yet to be elucidated, GLP-1 analogs have been shown to influence cancer cells by altering proliferation, apoptosis, ECM remodeling and the response to chemotherapy $(17,18,19)$.

We studied several aspects of ovarian cancer progression such as apoptosis and migration, as well as metalloproteinase production associated during these processes. Consistent with the work of He and collaborators (19), we show that Exendin-4 suppresses ovarian cancer migration and induces apoptosis by the activation of GLP-1R in human ovarian cancer cells. Ovarian cancer patients are currently treated with platinum-based drugs and taxol (50); however, the results of this study indicate potential additive or synergic effect of incretinchemotherapy treatment. Besides its anti-cancer effects, we observed anti-inflammatory effects, which are partially mediated by modulation of the NF- $\mathrm{kB}$ signaling pathway.

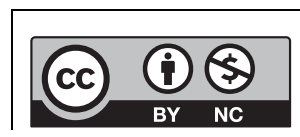

This work is licensed under a Creative Commons Attribution-NonCommercial 4.0 International License. 
A

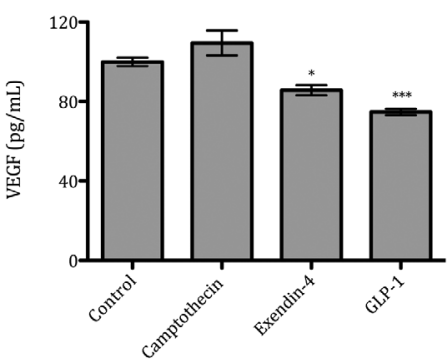

D

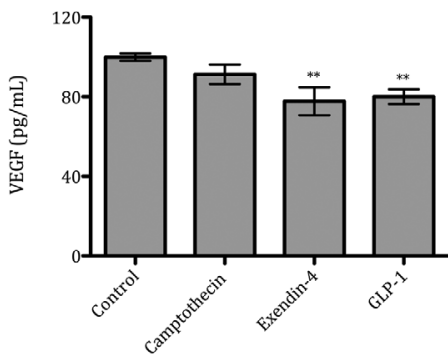

B

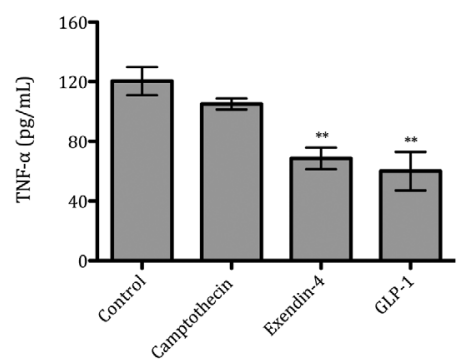

E

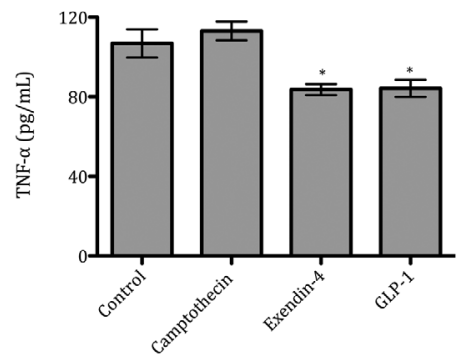

C

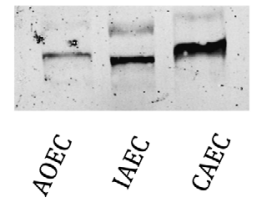

$\mathrm{F}$

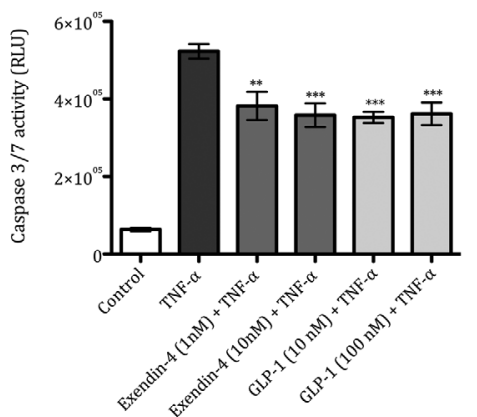

Figure 4 VEGF, TNF- $\alpha$ concentration in ovarian cancer cells and Caspase 3/7 activation in endothelium. VEGF protein levels in SKOV-3 (A) and CAOV-3 (D) and TNF- $\alpha$ protein levels in SKOV-3 (B) and CAOV-3 (E) after $24 \mathrm{~h}$ incubation with Camptothecin (100 nM), Exendin-4 (50 nM) and GLP-1 (100 nM). Representative Western blot image of GLP-1R expression in human Aortic Endothelial Cells (AoEC), Iliac Artery Endothelial Cells (IAEC) and Coronary Artery Endothelial Cells (CAEC) (C). Caspase 3/7 activation in TNF- $\alpha(10 \mathrm{ng} / \mathrm{mL})$ stimulated IAEC after incubation with Exendin-4 (1 nM and $10 \mathrm{nM})$, and GLP-1 (10 nM and $100 \mathrm{nM})(\mathrm{F})$. Mean values \pm S.E.M. are shown. $n=3-6$ per group. ${ }^{*} P<0.05, * * P<0.01, * * * P<0.001$ TNF- $\alpha$ vs different conditions. One-way ANOVA followed with Dunnett's post hoc.

During early ovarian carcinogenesis, inflammatory mediators such TNF- $\alpha$ and TLR4 $(27,28)$ activate NF-кB signaling pathway by activation of the IKK complex, which then phosphorylates IкB. Phosphorylated I $\kappa$ B is then ubiquitinated and degraded by the proteasome system, leading to the release of NF-kB. The NF-kB molecule then translocates to the nucleus and initiates the transcription genes associated with metastasis, proliferation angiogenesis and suppression of apoptosis (29). We observed that treatment with Exendin- 4 inhibits phosphorylation of IкB, hence the activation of the NF-кB signaling pathway.

Reasons for the high mortality rate associated with ovarian cancer include a late diagnosis, at which time cancer has metastasized throughout the peritoneal cavity. Ovarian tumor cells and the surrounding stromal cells stimulate the synthesis or activation of a family of proteolytic enzymes known as the MMPs to aid in tumor growth, invasion and eventual metastasis $(12,30)$. The MMP activity is controlled by their inhibitors, TIMPs. Thus, any disturbances in MMP/TIMP balance determine the type of tumor microenvironment which may facilitate metastasis (12). Studies have shown that
() 2017 The authors Published by Bioscientifica Ltd
MMP-9 overexpression is associated with an increased metastatic potential of ovarian tumors, which leads to poor prognosis and decreased survival (31). In another study, elevated levels of MMP-2 in serum were used as an indicator of the severity of invasion in breast cancer (32). Although the expression pattern of each individual MMP varies depending upon the type of tumor, tumor stage, patient diagnosis and even potentially the patient population (33), studies have shown that a reduction in MMP production reduces the metastatic potential of cancer cells (34). In this study, we have shown that incretin drugs can reduce the expression of several MMPs under TNF- $\alpha$-mediated inflammatory environment in SKOV-3 cancer cell line. Furthermore, we were not able to assess detectable protein levels of MMPs in CAOV-3.

We studied the potential crosstalk between cancer cells and endothelial cells by analyzing the production of MMPs, cytokines such as VEGF, TNF- $\alpha$, IL- 6 by both cells types in vitro. These inflammatory mediators are recognized as an important component of the tumorstroma interaction which may predispose to angiogenesis, invasiveness and increases in metastasis potential $(35,36$, 37). We found that VEGF protein levels, a key molecule

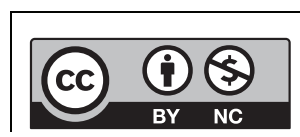

This work is licensed under a Creative Commons Attribution-NonCommercial 4.0 International License. 
A

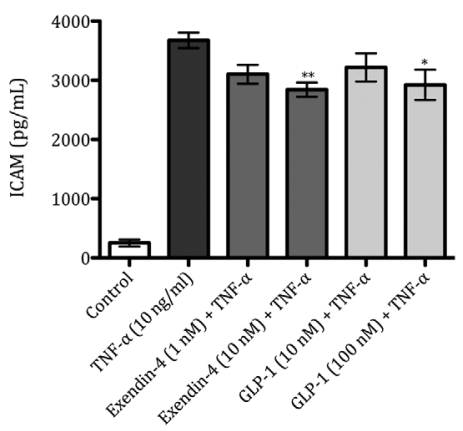

D

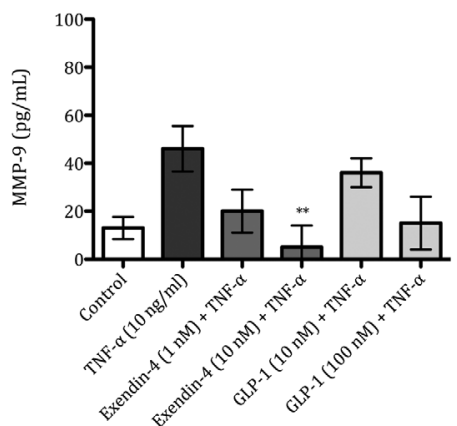

B

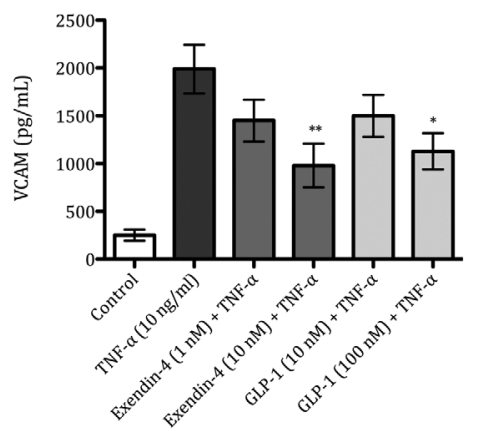

E

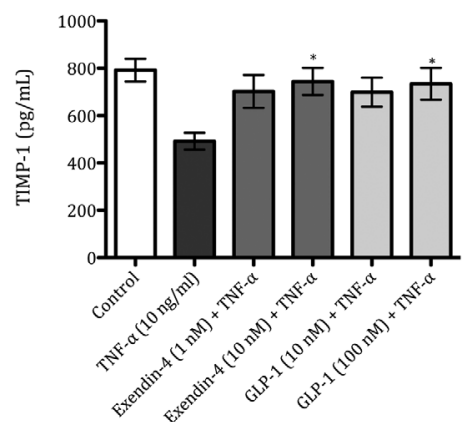

C

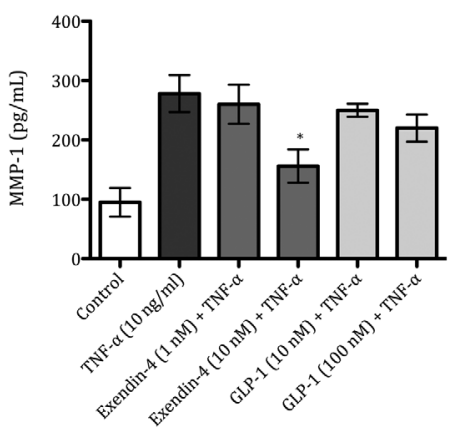

$\mathrm{F}$

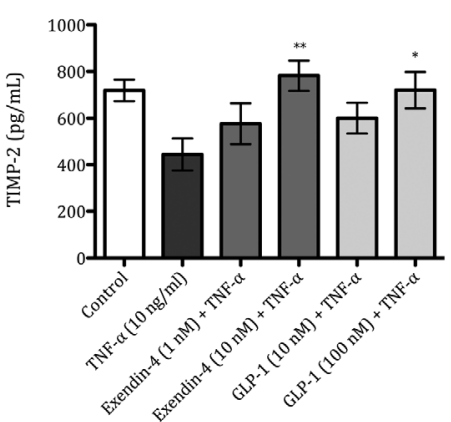

Figure 5 Exendin-4 modulates endothelial-cell response after TNF- $\alpha$ stimulation. Iliac Artery Endothelial Cells (IAEC) were stimulated for $24 \mathrm{~h}$ with TNF- $\alpha$ (10 ng/mL), Exendin-4 (1 nM and 10 nM) and GLP-1 (10 nM and $100 \mathrm{nM})$. Protein concentration of VCAM-1 (A), ICAM-1 (B), MMP-1 (C), MMP-9 (D), TIMP1 (E) and TIMP-2 (F). Mean values \pm S.E.M. are shown. $n=6$ per group. $* P<0.05, * * P<0.01$ TNF- $\alpha$ vs different conditions. One-way ANOVA followed with Dunnett's post hoc.

involved in neovascularization $(38,39,40)$, were reduced in cancer cells after incretin drug treatment. Ovarian cancer inflammatory mediators such as TNF- $\alpha$ and IL-6, which are elevated in ovarian cancers (41), were also reduced upon incretin drug treatment.

Interestingly, recent investigations revealed a new mechanism by which cancer cells interact with endothelial cells during metastasis progression. In contrast to leukocyte transendothelial diapedesis, the research indicated that cancer cells can induce programmed cell death of the endothelial cells, hence promoting extravasation and metastasis (42). Through a series of in vitro experiments, the authors demonstrated that cancer cells can trigger the death of endothelial cells in a process mediated by TNF- $\alpha$ and MMPs $(43,44)$. In our study, we found that incretin drugs can reduce the TNF- $\alpha$ protein levels in both cancer cell lines, whereas the levels of other inflammatory cytokines were not affected. Furthermore, incretin drugs can influence vascular biology due to the presence of GLP-1R in endothelial cells. Consequently, in order to reproduce the effects that tumor cell may exert on endothelium at the moment of extravasation and metastasis, endothelial cells were stimulated with TNF- $\alpha$

$\begin{array}{lr}\text { http://www.endocrineconnections.org } & \text { ○ } 2017 \text { The authors } \\ \text { DOI: } 10.1530 / \text { EC-17-0294 } & \text { Published by Bioscientifica Ltd }\end{array}$

and treated with GLP-1R agonists. Contrarily to the effects in ovarian cancer cells, we have observed that incretin drugs prevent apoptosis of endothelial cells.

Ovarian cancer progression is characterized by the production of inflammatory mediators such as TNF- $\alpha$ and IL-1 (45). Studies have shown that these inflammatory molecules mediate the expression of endothelial adhesion molecules VCAM-1 and ICAM-1 (46, 47). Changes in the expression of cell adhesion molecules have been implicated in all steps of tumor progression, including migration of cells from primary tumor site to circulation, intravasation into the blood stream, extravasation to secondary metastatic places and formation of new tumors (48). Interestingly, we have shown that incretin agonists can reduce the expressions of both VCAM-1 and ICAM-1 adhesion molecules in endothelial cells suggesting a potential role of incretin drugs in reducing the metastatic potential of cancer cells. Additionally, production of metalloproteinases by endothelial cells is also a critical event during angiogenesis that occurs under normal and tumorigenic conditions (49). We observed a decrease in MMP-1 and MMP-9 production accompanied by an increase in the corresponding TIMPs.

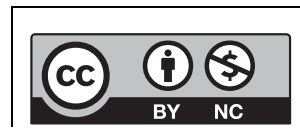

This work is licensed under a Creative Commons Attribution-NonCommercial 4.0 International License. 
Due to the hidden potential of incretin drugs as anti-cancer drugs, this study aimed to provide further understanding of the role of incretin drugs on tumor progression. Our work indicates that the pleiotropic effects of incretin drugs are not limited only to glucoselowering actions, but incretins also modulate the actions of both ovarian cancer cells and endothelial cells involving several aspects of tumor progression. Although the synergic effects of anti-tumor and incretin therapy on tumor progression yet remain to be studied, incretin alone has shown great potential in the ovarian cancer field.

\section{Supplementary data}

This is linked to the online version of the paper at http://dx.doi.org/10.1530/ EC-17-0294.

\section{Declaration of interest}

The authors declare that there is no conflict of interest that could be perceived as prejudicing the impartiality of the research reported.

\section{Funding}

This work was supported by grants from the Medical University of Silesia KNW-1-076/K/6/0 and KNW-1-018/N/5/0.

\section{References}

1 Carstensen B, Read SH, Friis S, Sund R, Keskimäki I, Svensson A-M, Ljung R, Wild SH, Kerssens JJ, Harding JL, et al. Cancer incidence in persons with type 1 diabetes: a five-country study of 9000 cancers in type 1 diabetic individuals. Diabetologia 201659 980-988. (doi:10.1007/s00125-016-3884-9)

2 Harding JL, Shaw JE, Peeters A, Cartensen B \& Magliano DJ. Cancer risk among people with type 1 and type 2 diabetes: disentangling true associations, detection bias, and reverse causation. Diabetes Care 201538 264-270. (doi:10.2337/dc14-1996)

3 Gallagher EJ \& LeRoith D. Obesity and diabetes: the increased risk of cancer and cancer-related mortality. Physiological Reviews 201595 727-748. (doi:10.1152/physrev.00030.2014)

4 Farooki A \& Schneider SH. Increased cancer-related mortality for patients with type 2 diabetes who use sulfonylureas or insulin: response to Bowker et al. Diabetes Care 200629 1989-1990. (doi:10.2337/dc06-0874)

5 American Diabetes Association Recommendations. Approaches to glycemic treatment. Sec. 7. In Standards of Medical Care in Diabetes 2016. Diabetes Care 201639 (Supplement 1) S52-S59.

6 Prasad-Reddy L \& Isaacs D. A clinical review of GLP-1 receptor agonists: efficacy and safety in diabetes and beyond. Drugs in Context 20154 1-19. (doi:10.7573/dic.212283)

7 Kim W \& Egan JM. The role of incretins in glucose homeostasis and diabetes treatment. Pharmacological Reviews 200860 470-512. (doi:10.1124/pr.108.000604)

8 Waser B, Blank A, Karamitopoulou E, Perren A \& Reubi JC. Glucagon-like-peptide-1 receptor expression in normal and diseased human thyroid and pancreas. Modern Pathology 201528 391-402. (doi:10.1038/modpathol.2014.113)
9 Lengyel E. Ovarian cancer development and metastasis. American Journal of Pathology 2010177 1053-1064. (doi:10.2353/ ajpath.2010.100105)

10 Weidle UH, Birzele F, Kollmorgen G \& Rueger R. Mechanisms and targets involved in dissemination of ovarian cancer. Cancer Genomics and Proteomics 201613 407-424. (doi:10.21873/ cgp.20004)

11 Al-Alem L \& Curry TE. Ovarian cancer: involvement of the matrix metalloproteinases. Reproduction 2015150 R55-R64. (doi:10.1530/ REP-14-0546)

12 Yeung T-L, Leung CS, Yip K-P, Au Yeung CL, Wong STC \& Mok SC. Cellular and molecular processes in ovarian cancer metastasis. A review in the theme: cell and molecular processes in cancer metastasis. American Journal of Physiology: Cell Physiology 2015309 C444-C456. (doi:10.1152/ajpcell.00188.2015)

13 Worzfeld T, Pogge von Stand mann E, Huber M, Adhikary T, Wagner U, Reinartz S \& Müller R. The unique molecular and cellular microenvironment of ovarian cancer. Frontiers in Oncology 2017724. (doi:10.3389/fonc.2017.00024)

14 Kessenbrock K, Plaks V \& Werb Z. Matrix metalloproteinases: regulators of the tumor microenvironment. Cell 2010141 52-67. (doi:10.1016/j.cell.2010.03.015)

15 Alarcon CR \& Tavazoie SF. Endothelial-cell killing promotes metastasis. Nature 2016536 154-155. (doi:10.1038/nature19465)

16 Ebrahem Q, Chaurasia SS, Vasanji A, Qi JH, Klenotic PA, Cutler A, Asosingh K, Erzurum S \& Anand-Apte B. Cross-talk between vascular endothelial growth factor and matrix metalloproteinases in the induction of neovascularization in vivo. American Journal of Pathology 2010176 496-503. (doi:10.2353/ajpath.2010.080642)

17 Fidan-Yaylali G, Dodurga Y, Seçme M \& Elmas L. Antidiabetic exendin-4 activates apoptotic pathway and inhibits growth of breast cancer cells. Tumor Biology 201637 2647-2653. (doi:10.1007/s13277015-4104-9)

18 Koehler JA, Kain T \& Drucker DJ. Glucagon-like peptide-1 receptor activation inhibits growth and augments apoptosis in murine CT26 colon cancer cells. Endocrinology 2011152 3362-3372. (doi:10.1210/ en.2011-1201)

19 He W, Yu S, Wang L, He M, Cao X, Li Y \& Xiao H. Exendin-4 inhibits growth and augments apoptosis of ovarian cancer cells. Molecular and Cellular Endocrinology 2016436 240-249. (doi:10.1016/j. mce.2016.07.032)

20 Garczorz W, Francuz T, Siemianowicz K, Kosowska A, Kłych A, Aghdam MRF \& Jagoda K. Effects of incretin agonists on endothelial nitric oxide synthase expression and nitric oxide synthesis in human coronary artery endothelial cells exposed to TNF $\alpha$ and glycated albumin. Pharmacological Reports 201567 69-77. (doi:10.1016/j. pharep.2014.08.007)

21 Planz B, Tabatabaei S, Kirley SD, Aretz HT, Wang Q, Lin C-W, McDougal WS \& Marberger M. Studies on the differentiation pathway and growth characteristics of epithelial culture cells of the human prostate. Prostate Cancer and Prostatic Diseases 20047 73-83. (doi:10.1038/sj.pcan.4500704)

22 Sharma M, Shubert DE, Sharma M, Rodabaugh KJ, McGarrigle BP Vezina C., Bofinger DP \& Olson JR. Antioxidant inhibits tamoxifenDNA adducts in endometrial explant culture. Biochemical and Biophysical Research Communications 2003307 157-164. (doi:10.1016/S0006-291X(03)01134-3)

23 Furukawa S, Soeda S, Kiko Y, Suzuki O, Hashimoto Y, Watanabe T, Nishiyama H, Tasaki K, Hojo H, Abe M, et al. MCP-1 promotes invasion and adhesion of human ovarian cancer cells. Anticancer Research 201333 4785-4790.

24 Jayasooriya RGPT, Park SR, Choi YH, Hyun J-W, Chang W-Y \& Kim G-Y. Camptothecin suppresses expression of matrix metalloproteinase-9 and vascular endothelial growth factor in DU145 cells through PI3K/Akt-mediated inhibition of NF-KB activity http://www.endocrineconnections.org DOI: 10.1530/EC-17-0294
C) 2017 The authors Published by Bioscientifica Ltd

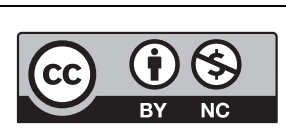

This work is licensed under a Creative Commons Attribution-NonCommercial 4.0 International License. 
and Nrf2-dependent induction of HO-1 expression. Environmental Toxicology and Pharmacology 201539 1189-1198. (doi:10.1016/j. etap.2015.04.011)

25 Alves C, Batel-Marques F \& Macedo AF. A meta-analysis of serious adverse events reported with exenatide and liraglutide: acute pancreatitis and cancer. Diabetes Research and Clinical Practice 2012 98 271-284. (doi:10.1016/j.diabres.2012.09.008)

26 Azoulay L, Filion KB, Platt RW, Dahl M, Dormuth CR, Clemens KK, Durand M, Juurlink DN, Targownik LE, Turin TC, et al. Incretin based drugs and the risk of pancreatic cancer: international multicentre cohort study. BMJ 2016352 i581. (doi:10.1136/bmj.i581)

27 Colotta F, Allavena P, Sica A, Garlanda C \& Mantovani A. Cancerrelated inflammation, the seventh hallmark of cancer: links to genetic instability. Carcinogenesis 200930 1073-1081. (doi:10.1093/ carcin/bgp127)

28 Mandai M, Yamaguchi K, Matsumura N, Baba T \& Konishi I. Ovarian cancer in endometriosis: molecular biology, pathology, and clinical management. International Journal of Clinical Oncology 200914 383-391. (doi:10.1007/s10147-009-0935-y)

29 Alvero AB. Recent insights into the role of NF-kappaB in ovarian carcinogenesis. Genome Medicine 20102 56. (doi:10.1186/gm177)

30 Steinkamp MP, Winner KK, Davies S, Muller C, Zhang Y, Hoffman RM, Shirinifard A, Moses M, Jiang Y \& Wilson BS. Ovarian tumor attachment, invasion, and vascularization reflect unique microenvironments in the peritoneum: insights from xenograft and mathematical models. Frontiers in Oncology 20133 97. (doi:10.3389/ fonc.2013.00097)

$31 \mathrm{Hu}$ X, Li D, Zhang W, Zhou J, Tang B \& Li L. Matrix metalloproteinase-9 expression correlates with prognosis and involved in ovarian cancer cell invasion. Archives of Gynecology and Obstetrics 2012286 1537-1543. (doi:10.1007/s00404-012-2456-6)

32 Liu S, Yang S, Yeh K, Yeh C \& Chiou H. Relationships between the level of matrix metalloproteinase-2 and tumor size of breast cancer. Clinica Chimica Acta 2006371 92-96. (doi:10.1016/j. cca.2006.02.026)

33 Henderson BE, Lee NH, Seewaldt V \& Shen H. The influence of race and ethnicity on the biology of cancer. Nature Reviews Cancer 2012 12 648-653. (doi:10.1038/nrc3341)

34 Almholt K, Juncker-Jensen A, Laerum OD, Dano K, Johnsen M, Lund LR \& Romer J. Metastasis is strongly reduced by the matrix metalloproteinase inhibitor Galardin in the MMTV-PymT transgenic breast cancer model. Molecular Cancer Therapeutics 20087 2758-2767. (doi:10.1158/1535-7163.MCT-08-0251)

35 Szlosarek PW. Expression and regulation of tumor necrosis factor in normal and malignant ovarian epithelium. Molecular Cancer Therapeutics 20065 382-390. (doi:10.1158/1535-7163.MCT-050303)

36 Coussens LM \& Werb Z. Inflammation and cancer. Nature 2002420 860-867. (doi:10.1038/nature01322)
37 Balkwill F, Charles KA \& Mantovani A. Smoldering and polarized inflammation in the initiation and promotion of malignant disease. Cancer Cell 20057 211-217. (doi:10.1016/j.ccr.2005.02.013)

38 Bamberger ES \& Perrett CW. Angiogenesis in epithelian ovarian cancer. Molecular Pathology 200255 348-359.

39 Markowska A, Sajdak S, Markowska J \& Huczynski A. Angiogenesis and cancer stem cells: new perspectives on therapy of ovarian cancer. European Journal of Medicinal Chemistry 2017 [in press]. (doi:10.1016/j. ejmech.2017.06.030)

40 Gómez-Raposo C, Mendiola M, Barriuso J, Casado E, Hardisson D \& Redondo A. Angiogenesis and ovarian cancer. Clinical and Translational Oncology 200911 564-571. (doi:10.1007/s12094-009-0406-y)

41 Gupta M, Babic A, Beck AH \& Terry K. TNF- $\alpha$ expression, risk factors, and inflammatory exposures in ovarian cancer: evidence for an inflammatory pathway of ovarian carcinogenesis? Human Pathology 201654 82-91. (doi:10.1016/j.humpath.2016.03.006)

42 Strilic B, Yang L, Albarran-Juarez J, Wachsmuth L, Han K, Muller UC, Pasparakis M \& Offermanns S. Tumour-cell-induced endothelial cell necroptosis via death receptor 6 promotes metastasis. Nature 2016 536 215-218. (doi:10.1038/nature19076)

43 Grootjans S, Vanden Berghe T \& Vandenabeele P. Initiation and execution mechanisms of necroptosis: an overview. Cell Death and Differentiation 201724 1184-1195. (doi:10.1038/cdd.2017.65)

44 Peter ME, Hadji A, Murmann AE, Brockway S, Putzbach W, Pattanayak A \& Ceppi P. The role of CD95 and CD95 ligand in cancer. Cell Death and Differentiation 201522 549-559. (doi:10.1038/ cdd.2015.3)

45 Wang X \& Lin Y. Tumor necrosis factor and cancer, buddies or foes? Acta Pharmacologica Sinica 200829 1275-1288. (doi:10.1111/j.17457254.2008.00889.x)

46 Tsoyi K, Jang HJ, Nizamutdinova IT, Park K, Kim YM, Kim HJ, Seo HG, Lee JH \& Chang KC. PTEN differentially regulates expressions of ICAM-1 and VCAM-1 through PI3K/Akt/GSK$3 \beta$ /GATA- 6 signaling pathways in TNF- $\alpha$-activated human endothelial cells. Atherosclerosis 2010213 115-121. (doi:10.1016/j. atherosclerosis.2010.07.061)

47 Mantovani A. Cancer: inflaming metastasis. Nature 2009457 36-37. (doi:10.1038/457036b)

48 Makrilia N, Kollias A, Manolopoulos L \& Syrigos K. Cell adhesion molecules: role and clinical significance in cancer. Cancer Investigation 200927 1023-1037. (doi:10.3109/07357900902769749)

49 Kobawala TP, Trivedi TI, Gajjar KK, Patel DH, Patel GH \& Ghosh NR. Significance of TNF- $\alpha$ and the adhesion molecules: L-selectin and VCAM-1 in papillary thyroid carcinoma. Journal of Thyroid Research 20162016 1-17. (doi:10.1155/2016/8143695)

50 Luvero D, Milani A \& Ledermann JA. Treatment options in recurrent ovarian cancer: latest evidence and clinical potential. Therapeutic Advances in Medical Oncology 20146 229-239. (doi:10.1177/1758834014544121)

Received in final form 10 October 2017

Accepted 17 October 2017

Accepted Preprint published online 17 October 2017 http://www.endocrineconnections.org DOI: 10.1530/EC-17-0294
(C) 2017 The authors Published by Bioscientifica Ltd

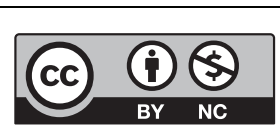

This work is licensed under a Creative Commons Attribution-NonCommercial 4.0 International License. 